\title{
The just transition of the European Green Deal and the development of the regions with intensive coal mining (example of Marishki Basin - Bulgaria)
}

\author{
Yuliana Yarkova $^{1 *}$, Dobri Yarkov², and Stoyanka Tsacheva ${ }^{1}$ \\ ${ }^{1}$ Trakia University, Department of Regional Development, Students Campus, Stara Zagora, Bulgaria \\ ${ }^{2}$ Trakia University, Department of General Livestock Breeding, Students Campus, Stara Zagora, \\ Bulgaria
}

\begin{abstract}
The just energy transition is an opportunity to drive a very important process of transformation of the traditional linear, waste holding economy based on fossil fuels and polluting transport to a new type of economy, driven by the circularity bio-, RES economics paradigm and environmentally responsible transport. The purpose of this study is to contribute to the identification of the direction, factors and mechanisms of the energy transition in the Marishki Basin - Bulgaria, as well as to formulate proposals related to the development of territorial plans for a just transition and the integrated development plans of the municipalities. The methods that have been applied to achieve the purpose of the research are qualitative - desk research (search for general information about the object and the subject of the research - offline and online) and an in-depth interview with leading experts (regarding the process of transition and transformation of the Maritsa East complex). In addition to subjective expert assessments, objective statistical data for the region and for the Maritsa East complex were used for the needs of the research. The present work summarizes the views of the leading experts and makes suggestions regarding the future economic development of the region concerned and its energy transition. The Marishki Basin is a region within which it is necessary to develop and implement a system of projects and measures to be set out in the integrated development plans of the municipalities concerned and to be part of the territorial plans for a just transition. The leading sectors are to bet agri-energ biotechnology, aquaponics, "hydrogen valleys", digital industries, robotics, urban agriculture, tourism and other activities that would create an innovative economic organism in the region.
\end{abstract}

\section{Introduction}

A just energy transition is not just a European policy transposed by national governments in national strategy documents for the 2021-2027 programming period. It is "a goad" (in Latin "stimulus") for local communities from the so-called carbon-intensive regions to encourage a process that could become the desired transition from a traditional linear, waste holding economy based on fossil fuels and polluting transport to a new type of economy driven by the circularity, bio-, RES- economics paradigm and environmentally responsible transport.

* Corresponding author: yu yarkova@abv.bg 
In all this, social justice and economic sustainability are the necessary and expected principles.

Under the EU's already set forth targets of carbon-neutral economy [1], national governments are offering their contribution, which is embodied in numbers to severely limit greenhouse gas emissions. The European Green Deal aims to reduce carbon dioxide emissions by $55 \%$ by 2030 compared to the base year 1990, and to achieve carbon neutrality by 2050 . With all this, however, let us bear in mind that there are strategic economic sectors, human destinies and cultural and historical traditions. Moreover, according to NSI data [2], in 1990 in Bulgaria 104.76 million tons of CO2 were emitted, and in recent years they have decreased, and in 2018 they are slightly above 40 million tons. These data suggest the overfulfillment of the target set forth for 2030, which draws our attention not only to carbon emissions from the country's carbon-intensive regions, but it is an occasion for discussion on the desired new paradigm of economy.

Our past transitions experience has shown that extending the lives of industries that are going to be closed is often accompanied by subsidies, higher costs for retraining, unemployment, health and the environment, as well as missed opportunities to diversify the economy [3]. Anna Zinecker et al. define the low-carbon energy transition as an energy transition involving the transition from high-carbon energy sources such as oil, gas and coal to low-carbon and zero-carbon energy sources such as RES. However, the skepticism of a number of authors [4] is not without reason in terms of the characteristics of the RES extraction facilities in the part that indicates a high need for fossil materials to build these installations. Another problem is that the integration of RES in the energy system has a very limited capacity to compensate for the closure of thermal power plants, so their intensive involvement is necessary, but it is only a part of the path of transformation, and the technology for production, installation and use of RES capacity must be based on environmental responsibility. The role of hydrogen in opening up new opportunities for energy flexibility, availability, security, as well as improved efficiency, contributing to the decarbonization of the economy, is increasingly being discussed [5], which means that RES can be an active part of the whole cycle of production and use of "green hydrogen".

Bulgaria will receive significant subsidies over the next seven years to move to a lowcarbon economy and to cope with the social consequences of this transformation, and the country will have to redirect over 1.2 billion euros in the same direction from the state budget, and from the future operational programs. In order to benefit from the just transition Funds, EU member states must draw up territorial plans for the transformation of the regions that are affected by the energy transition, which is still in the process of being launched in the affected Bulgarian regions.

There is an active discussion on the idea of energy independence at the community level, incl. of individual households. The European Directives are undoubtedly a regulatory prerequisite in this direction: the Internal Electricity Market Directive (Directive (EU) 2019/944), the Directive on the energy promotion from renewable sources (Directive (EU) 2018/2001), the European Directive on the energy characteristics of buildings (EU) 2018/44), the Energy Efficiency Directive (Directive (EU) 2018/2002), as all of which will be integrated into Bulgarian legislation. According to the draft Program for the Development of the Regions 2021-2027 (www.bgregio.eu), measures taken to increase the energy efficiency of public and residential buildings are eligible for funding under both main priorities of the program - Priority 1 for integrated urban development and Priority 2 for integrated territorial development of Level 2 planning regions (NUTS 2). The National Plan for Reconstruction and Sustainability of the Republic of Bulgaria also aims to promote economic and social recovery from the crisis caused by the COVID-19 pandemic. One of the key areas in it is the circular and low-carbon economy, a part of the measures which include improving the energy characteristics of residential and public buildings. This will create less need for the produced 
energy mostly in the large energy complexes, which becomes a natural prerequisite for limiting the energy from TPPs. However, market mechanisms also intervene here, which have not yet been finalized in order to clarify the scale and parameters of the process. Bulgarian energy policy expert Slavcho Neikov draws our attention to a number of other issues that must be avoided in the legislative and regulatory framework of a just transition, which we also believe is particularly important, including in relation to market structures and mechanisms - both existing and being newly created ones.

The study is organized as follows. Following this introduction, Section 2 presents the goal, subject and methods of the study. Concepts on regional economy and its factors and specific process of energy transition are presented in section 3. Synthesis of results from conducted in-depth interviews is presented in Section 4. Conclusions and recommendations are presented in Section 5 of the paper.

\section{Goal and methods of the study}

The goal of this study is to contribute to the identification of the direction, factors and mechanisms of the energy transition in the Marishki Basin in Bulgaria, as well as to formulate proposals related to the development of territorial plans for a just transition and integrated development plans of municipalities. Real transformation, defined as a just energy transition, is possible through inclusive discussions of all the parties concerned to address the challenges and increase opportunities. The focus of this study is the opinion of key experts on the transition in the largest energy region of the coal industry in Bulgaria - the Marishki Basin.

The object of transformation is not just the Marishki Basin, but the economic system of the region - administrative area of Stara Zagora (NUTS 3), the municipalities where the open pit mines and energy complexes are located (municipalities of Galabovo and Radnevo), as well as other municipalities, where the labor force of the energy complex comes from.

The methods applied to achieve the goal of the study are qualitative - desk research (search of general information about the object and subject of the research - offline and online) and in-depth interview with leading experts (regarding the transition process and transformation of the Maritsa East complex). In addition to subjective expert assessments, objective statistical data for the region and for the Maritsa East complex have been used for the needs of the study.

The subject of the analysis are problems and opportunities in connection with the energy transformation of the region. We had semi-structured interview through the so-called "Guide" of five main topics (questions) on which the conversation with the experts was conducted, as follows: If we make the final solution to close coal mining in the Marishki Basin, what will we replace energy production with and how? How long does it make sense to maintain the mines, why and how? Could the power plants in the Marishki Basin be preserved and on the basis of what resource would they be able to produce energy? How can the economic, social and environmental interests of the local population be protected? What is the place of the "bottom-up" approach in a just transition? In order to go into more details, additional questions to each expert have been asked.

\section{Literature review}

\subsection{Modern development of regional economy in the context of a just energy transition}

Economic activity arises and develops in the so-called spatial medium, which is an irrevocable factor for the functioning of the economic system and is essential for the 
competitiveness of the local/regional economy. Quantitative and qualitative disequilibrium in the spatial distribution of resources and economic activities preconditions different returns on investment for production factors, different levels of social welfare, as well as different opportunities for impact on local/regional development [6]. As Hoover [7] points out, the regional economy is the form in which the territorial nature of the economic system manifests itself.

The statement of the Swiss civilization critic Denis de Rougemont [8] from the late last century does sound relevant and strong in 2021, namely that the state is too small to solve the global problems of our time and too big to recognize the problems of local communities, emphasizing in his work "The Future is our Affair" the role of the regional economy and its management for a real improvement of the quality of life in the communities.

As regards the factors of regional economy dynamics, the theory and models suggest a different focus. According to a number of authors [9-11] the main engine of the regional economic development is the demand for regional production and the provision of labor and other resources. Other authors emphasize alternative market power (supply) as a driver of economic development [12-14]. But we must look at the regional economic growth today more and more in the context of the new conditions for the world economy - the strong impact of the new technologies, informatics, environmental efforts, climate, pandemic and social challenges. Only the COVID crisis in the last year has closed a number of regional businesses, raised unemployment and severely limited mobility, and regions are looking for their rescue business models.

As Rost [15] stated more than a decade ago, "a region is perfectly formed when it can provide for the basic needs of the population on its own (food, housing, education, culture, health care, regional transport, regional communications) and besides it can offer special goods and services to the global market to use the revenues for purchasing foreign goods and services... This applies to all regions of the world, whether they are in developing or developed countries."

On the one hand, the socio-economic prosperity of places and regions is very closely tied to the vital economic activity of economic agents, because business development has a direct impact on competitiveness, innovation and employment. On the other hand, against the background of the global provocative medium, the intangible assets are beginning to play an increasingly key role in the regional development - human capital (education, qualification, knowledge, skills) and social capital in general (information, contacts, networks, synergies). A number of contemporary authors cite as one of the leading factors for local development and local academic centers [16]. Therefore, in search of the way to transform the regional economy, we will have to draw our attention not only to an impact on the economic components of the regional system, but also on the favor of purely human and social factors in order to preserve communities and territories as living organisms. The concept we need to build on is the adoption of the regional economy as a complex system composed of diverse subsystems/activities, which only in integration and balance can ensure the overall regional economic growth and well-being of the population.

We must also pay attention to the fact that the creation of a value at the local/regional level is both a basis for economic prosperity and a form of crisis situation control that increasingly accompanies our time. This is also a prerequisite for independence of the local community, meeting the socio-cultural needs and preserving the community identity. Let us bear in mind that these processes also have their political dimension, which refers to political decision-making and participation of individual social groups in the process of elaborating development policies [17]. It is especially important to take this aspect into account in the just transition of the affected coal regions, working out specific ideas and projects related to the development of low-carbon, circular, bio-economy, which will find an institutional 
expression in the plans for integrated development of municipalities and territorial plans for a just transition.

We pay particular attention to the belief that new business models must be closer to the natural laws in force in the ecosystems of the planet Earth. We have a number of examples of models of local economic development based on the application of physical laws, such as Weber's model for localization of industry [18], the Law of Retail Gravitation model of Reilly [19], and others. The elaboration of such models gives hope that the new economic paradigm would ensure the desired sustainable development and social progress. Certainly, that is possible by combining the knowledge, efforts and will of the local community, governing bodies at local, regional and national level, trade unions, scientists from various scientific fields (physicists, ecologists, power engineers, agrarians, economists, etc.).

It is clear that the development so far of such regions as the Marishki Basin in Bulgaria is related to natural resources - the availability of fossil fuels (lignite coal). But even August Lösch [20] shows that factors other than natural also play an important role to explain the territorial economic structures. Therefore, the demand of the affected regions must be focused on building a new competitive power and quality of life of the local population, both by using identified available factors and by attracting resources with high returns and sustainability.

A just transition in Europe is already applied as a set of guiding principles, as set out in the Guidelines for a Just Transition [21]. According to Hirsch, Matthess \& Fünfgelt [22], this approach is taken by many interested parties, such as the Center for Just Transition of the International Trade Union Confederation, countries such as Canada, Germany and Spain, as well as research and non-governmental organizations.

The British E3G Think Tank published a report on this subject in 2019, which covers coal regions in the Czech Republic, Poland, Slovakia, Greece [23] "In all these countries, coal is a major part of the energy mix, but their production is declining as a result of the decrease in the competitive power of the sector".

A number of new achievements can be discussed in relation to ways of reducing the energy consumption and limiting the carbon emissions, but Prof. Dr. André Faaij, Director of Science, ECN part of TNO emphasizes that there is no energy transition without transforming the industry. He believes that energy efficiency and a variety of energy sources are not the definitive solution to the problem; instead, we need to consider the diversity of industrial processes [5].

Some regions of Europe are already on the path to energy transition and have ready-made solutions and good practices. In the region of Lausitz, East Germany, where the main economic driver is the production of energy from coal, a solution has been found: the open coal mine pits are being transformed into biomass fields; the three power plants retain their function, but after they had been transformed into those ones for biomass energy production. In the Ruhr region, West Germany, as a result of intensive negotiations between the social partners, programs for redistribution of workers to other sectors were launched back in the 1990s, wage increases were limited, early retirement and relevant compensation was introduced. Existing and future skills needed at the local level have been identified, and priority areas have been established. An individual strategy for transition to another job has been created for each employee. Of course, other regions in Europe have their own experience with the challenges and opportunities of the energy transition, which might be studied and used for the conditions in the Marishki Basin.

\section{Empirical results and discussion}

In Bulgaria, $48 \%$ of electricity is produced by coal-fired power plants, which are the main base capacities [24]. The Marishki Basin provides lignite coal for the Maritsa East industrial complex, which provides $30 \%$ of Bulgaria's electricity production, thus making it the largest 
energy complex in Southeast Europe [25]. "Mini Maritsa-East" EAD is the company with the largest coal production in Bulgaria, which provides energy supplies to the Maritsa East thermal power plants.

The Stara Zagora district, on whose territory are the capacities for electricity production based on the coal mining industry, ranks 2 nd in the country of the 28 regions in 2018 , following the Sofia-capital district (According to NSI data, GDP - regional level) by index level of economic development, as being measured by GDP per head (GDP/capita). The energy and mining industries bear responsibility for $33 \%$ of the value of regional production. The contribution of the Stara Zagora district in the country's GVA is 5\%. In 2018, the industry generated BGN 2,928 million $-61.5 \%$ of GVA in the region with a $25.78 \%$ share of this sector in the country. In second place in the region are the services - with BGN 1,679 million GVA and share of $35.28 \%$. The agricultural sector has the lowest share of $3.2 \%$. The municipalities of Galabovo and Radnevo have the largest contribution to the generated production. According to NSI data, in 2018 the highest salaries in Stara Zagora district are offered by the sectors of energy (BGN 2,353) and mining industry (BGN 1,972) at an average level for the region of BGN 1,099, which is the third highest level in the country after Sofiacity and Sofia-district. At the municipal level, wages above the regional average are received only by those employed in the municipality of Radnevo (BGN 1,657) and the municipality of Galabovo (BGN 1,610), on whose territory coal and energy is produced respectively. Despite the strong specialization of the Stara Zagora district in mining and energy industries, manufacturing and trade are those activities that provide the most jobs and have the largest share in the economic results of the area [26]. The field of education and "professional activities and research" branch have also shown a potential for growth. The agricultural sector has fostered a growth in its contribution to the regional economy and an increased contribution to the region's GVA. This, together with the available conditions, resources and experience, define the agriculture as an irrevocable economic activity for the regional economic structure, which, however, needs a support program to solve specific problems and to be actively involved in the process of diversification of the regional economy. The tourism industry has reported progress in development, but the tourism capacity of Stara Zagora district and its opportunities for valorization of tourist resources and for creation of new jobs are much higher.

As a result of the inevitable economic transformation, the strongest economic, social and demographic impacts are expected at the local level - in the municipalities of Galabovo and Radnevo. Energy and coal mining in the region integrate between 12.5 thousand and 15 thousand people working in the two sectors. Employees in both sectors are also attracted from other municipalities on the territory of Stara Zagora district, Yambol district, Haskovo district, Sliven district. There are also many relevant business entities around the thermal power plants in the area, which provide transport, food, clothing and medical services for those working there. Table 1 shows a synthesis of the results of the in-depth interviews with experts in connection with their views on the transition in the largest energy region in Bulgaria based on the coal mining industry - Maritsa East complex.

In the study we have included experts with regard to the issues concerned, as follows:

Slavcho Neikov - Chairman of the Board of the Institute of Energy Management, Bulgaria; Boyan Rashev - Managing partner of consulting company DENKSTATT; eng. Simeon Beloreshki - Consultant in energy projects in the Middle East and Asia; eng. Ivan Hinovski - Chairman of the Bulgarian Energy and Mining Forum - Bulgaria; eng. Ivan Markov - Executive Director 2005 - 2009 of "Mini Maritsa East" Mines, Deputy Minister of Energy in 1991 and in the period of 1995-1997; eng. Shteryo Shterev - Vice-Chairman of the Scientific and Technical Union for Mining, Geology and Metallurgy. Executive Director of "Mini Maritsa East" EAD in the period of 2001-2005; Georgi Stefanov - WWF -Bulgaria, 
expert in political and legislative standpoints in the field of climate and energy policies at the national and European level.

Of course, a detailed presentation of the in-depth interviews is not possible, but below are presented the key points of the shared opinions on each of the questions asked.

Answers from the in-depth interviews with experts:

- Question № 1: If we make the ultimate solution to close the coal mining in the Marishki Basin, what will we replace energy production with and how?

Slavcho Neikov: There is no ultimate solution to close coal mining. Gradual replacement with natural gas, nuclear energy, hydrogen, renewable sources, etc. Use of energy storage technologies.

Boyan Rashev: With a combination of nuclear and gas power, RES and biomass are insignificant.

Eng. Simeon Beloreshki: Without knowing the time when this is going to happen, we can't answer definitively.

Eng. Ivan Hinovski: We can procrastinate as much as we want, but rising prices of the emitted carbon will drastically increase the production costs of the coal-fired power plants over all others and in a liberalized market, as is the case with the Bulgarian and regional markets, there will be no one to buy this energy.

Eng. Ivan Markov: Shutting down coal mining is the ultimate solution. There is no way we can compensate for the loss of electricity. During the peak loads, photovoltaic power plants usually do not function, wind power plants are always in question, and hydropower plants that are over 100 can never operate with a coefficient of simultaneity of 1 . In other words, without coal-fired power plants in our country it will be difficult to collect more than $5,500 \mathrm{MW}$ of electricity generating capacity, i.e. a shortage in the range of 2,000 MW is formed. In addition, we should take into account that the technical possibilities for import of electricity through the existing power lines are 1,590 MW. Even if all the neighboring countries have capability, respectively interest to sell electricity to us in the peak hours there will be a regime of economy in Bulgaria.

Eng. Shteryo Shterev: If the coal mining in the Maritsa East EAD Mines is stopped without prior preparation in 2025, it will be a complete disaster - energy, economic, social, ecological. Bulgarian energy industry does not have reserve base capacities to cover the loss of over 3,100 MW, currently operating in Maritsa East. Such cannot be built in 5-6 years. There are no redundant capacities in our Balkan neighbors, since we export for them. Not in Europe either. The exposed coal seams are prone to spontaneous self-ignition. Underground fires are very difficult to put out. For decades, the region's air will be polluted by fire emissions. The boards of the mines will collapse and become impassable swamps with floating sands, which will be dangerous for both humans and animals. The mines will be filled up with groundwater and surface water, which will subsequently be oxidized. The disaster will really be complete.

Georgi Stefanov: The issue is common to the EU and there must be common solutions. Huge areas have great potential, and the common European market is a guarantee for the energy system, because if necessary, electricity can always be taken from another point.

- Question № 2: How long does it make sense to maintain the mines, why and how?

Slavcho Neikov: Until 2025 with the legal support of the state. Then the market mechanisms will work.

Boyan Rashev: While TPPs are coal fired.

Eng. Simeon Beloreshki: If we have a financial resource like Germany, it would be best until 2038, but this is not real. Construction of alternative capacities / 7-10 GW /. The problem would be not so much the funding as the project readiness.

Eng. Ivan Hinovski: Mini Maritsa East EAD needs to be restructured by limiting production in the period of 2022-2024. 
Eng. Ivan Markov: Up to the complete taking of all the coal reserves, even those outside the concession circuit. The explanation for this is logical: investments have been made in personnel, technology, equipment, and a cost-effective necessary product is being produced.

Eng. Shteryo Shterev: The mines must continue to operate at least until they build and introduce equivalent power and safety power generation facilities. At the same time, they have to implement a project to bring the non-working mine boards into long-term sustainability, where they will work at a higher rate at the opening-up than the current one.

Georgi Stefanov: Currently, due to the low calorific value of coal from the basin, we have a high-cost price of energy and we have to ask ourselves whether to burn them or get other products from them with higher added value. Spain, Italy, Portugal use them not for electricity, but for other industries and branches, such as the chemical industry, metallurgy.

- Question № 3: Can the power plants in the Maritsa East complex be preserved and on the basis of what resource will they be able to produce energy?

Slavcho Neikov: The preservation of the so-called "American power plants" must be a national priority. They provide at least $17 \%$ of the country's energy.

Boyan Rashev: If they switch to gas, they would be able to operate for another half century.

Eng. Simeon Beloreshki: I am not very optimistic, unless we witness a breakthrough in $\mathrm{CO} 2$ capture and storage technologies. Power plants can produce solar energy and use medium and high voltage networks.

Eng. Ivan Hinovski: The power plants can be replaced Unit by Unit gradually: initially by mixing coal and biomass to reduce carbon emissions, then replacing part of the Units with new high-efficiency steam-gas (binary) natural gas technologies and, at a later stage, - by hybrid renewables, hydrogen and steam-gas modules.

Eng. Ivan Markov: Is it worth the TPP switching to gas? No, it is not. It is most costeffective to continue to use coal as a fuel base by implementing modern environmentally friendly technology, which, moreover, is being done in "Maritsa East".

Eng. Shteryo Shterev: The power plants can be reconstructed to use natural gas. But this will require significant funding. New gas pipelines will also be required for the needs of these plants.

Georgi Stefanov: American power plants can run on liquefied gas, and American one"

- Question № 4: How can the economic, social and environmental interests of the local population be protected?

Slavcho Neikov: Creation of a new type of production, incl. and based on a new type of technology, a new approach to training and retraining of those already employed.

Boyan Rashev: With difficulty. The State does NOT protect the interests of the people.

Eng. Simeon Beloreshki: Not to be protected, but let the State offer new opportunities.

Eng. Ivan Hinovski: TPPs need and will be modernized, the soles of the mines can be recultivated and afforested with fast-growing energy crops, another part of them can be turned into sites of generating capacity of RES or sites for production of green hydrogen for transport purposes. The large-scale conversion will not only preserve the existing jobs, but according to our estimates will open many new ones for young highly skilled specialists, and it will bring about one of the most modern regional developments in this country.

Eng. Ivan Markov: The European Commission is offering us 458 million euros to liquidate all the coal-fired power plants, Maritsa East Mines and, in fact, Bulgaria's energy independence. Hopefully these funds will be used to create conditions for new businesses based on modern high-tech technologies.

Eng. Shteryo Shterev: It is necessary to find investors in advance to build factories and plants whose products should be in demand and competitive at European and world markets. 
Georgi Stefanov: It is very important that the parties concerned are directly asked what they expect in the future. For the first time, we have the opportunity to prevent the disintegration of an entire.

- Question № 5: What is the place of the “bottom-up” approach in a just transition?

Slavcho Neikov: In practice, this means that the role of the local government, NGOs, business, trade unions is essential. As well as the role of the EU in this process, it is particularly important in two ways - securing the funding for a just transition and creation of the legal framework for its use.

Boyan Rashev: I don't see the place of the approach in this particular case because it's imposed from the outside.

Eng. Simeon Beloreshki: Just transition is unfortunately a rather streamlined term and people have different ideas and expectations, and that means only one thing - most people will be disappointed.

Eng. Ivan Hinovski: This approach can make a significant contribution to the success of the region's conversion by integrating modern energy engineering solutions with socioeconomic policies, the development of new areas of higher education in the region, making the regions the first hydrogen public transport, getting the public opinion "to be heard" and involving the private initiative. Today, the most disastrous policy in this direction is to wait for the State to say what to do, because the two largest investors in the Bulgarian energy sector work in the region and their experience and contribution can be decisive.

Eng. Ivan Markov: The "bottom-up" approach is identical to "from the private (singular) to the general", i.e., the interests of the community are formed by those of its constituent individuals, which a priori requires and imposes their coherence.

Eng. Shteryo Shterev: If there is a truly just "bottom-up" transition, it must first and foremost ensure that the living standards of Bulgarians are equal to the average ones of the Europeans, whose "green" leaders impose this transition through high prices for carbon allowances.

Georgi Stefanov: A key point is the "Clean Energy" package. Municipalities must now have teams that know the attitudes of the people, their expectations, opportunities and offer the best for the area.

\section{Conclusion}

A just energy transition directed to change practices in energy production and consumption is directly connected with regional/local development. This is because the aim of this transition is, on the one hand, to minimize the negative impact on communities and those employed in the high-carbon sectors, which have to be transformed gradually. On the other hand, to maximize the positive opportunities for new jobs in the low-carbon sectors and to ensure an environmentally responsible development trajectory for these regions.

The Marishki Basin is a region within which it is necessary to develop and implement a system of projects and measures to be set out in the integrated development plans of the municipalities concerned and to be part of the territorial plans for a just transition, which according to our current study includes:

1. Transformation of coal energy production is inevitable, both on the occasion of commitments made for a low-carbon and carbon-neutral economy and as a result of market signals and processes that indicate that technological development leads to more efficient, sustainable and competitive methods and technologies. So, the national planning documents must reflect the going out of the TPPs to the free market after 2025. It is expected to rest against the created appropriate regulatory and economic conditions for a transition to the extraction and use of "clean energy", integration of technologies for CO2 capture and storage, for production and industrial use of green hydrogen, for environmentally responsible by- 
products of coal mining. Such a policy is necessary because coal replacement is a process that will take years and the state must have a clear and adequate strategy and program, reflecting the trends of the energy market, which is liberalizing and more open to the European one.

2. It is evident that the mine excavations are a serious environmental problem, which is exacerbated by the lack of systematic recultivation of the affected areas. New "opening-ups" would deepen the crisis, which we actually aim to stop. It is clear that the existing coal "opening-ups" will continue to be used for the period until the energy complex is transformed. Although a number of technological proposals have been developed for the environmentally responsible use of lignite coal (ecological coal processing, ammonia manufacture from coal, ethanol manufacture from coal, etc.), the environmental problem with the excavations is not solved. We propose to develop and implement a comprehensive environmental program related to the already opened mining areas: bringing the descending galleries of the mine boards into long-term sustainability; control of groundwater and surface waters that fill the excavations; stopping new opening-ups and final tamponage of the coal seams and the formation of the outlying mine pits; active recultivation of the areas disturbed by the mining excavations and their being included into active economic and ecological practices.

3. Taking into consideration the relatively slow and gradual transition, it is expected that some workers in open pit mines and TPPs will enter retirement age in the medium term, which means that from a social point of view, it is important to carry out a research of the structure (by age, education, place of residence, etc.) of those employed in the mines and TPPs, as well as their intentions for future realization. Thus, it will be rationalized the working-out of a program for social adaptation, including the personal preferences of employees; introduction of a new approach to the training and retraining of workers in mines and TPPs. Of course, expectations should not be tied only to the conversion of jobs on the site of transformed mines and power plants. It is through the diversification of the region's economy that employment can be provided in the municipalities, from where workers are transported every day by hundreds of buses.

4. A design-grounded nature of funding for effective programs of initiatives at the local and regional level continues during the 2021-2027 programming period as well. Therefore, all scientifically based ideas and programs, on the one hand, should be elaborated through application of the "bottom-up" approach and, on the other hand, should be brought into being in specific design solutions that have to be incorporated into the integrated development plans of the vulnerable municipalities for the period of 2021-2027. Some sectors that are already proving their potential and perspective for the region are modern and sustainable food manufacture combined with energy production, as well as increasingly active accommodation of companies from the IT sector in the region. Designs that are needed to rapidly deploy these sectors are aimed at agri-energy, biotechnology, aquaponics, "hydrogen valleys", digital industries, robotics, urban agriculture, tourism and other activities that would create an innovative economic organism in the region. Even for the flow-line and other types of infrastructure, which is not integrated in these projects and it remains as the so-called "brownfields" needs to work out a concept for future use, incl. through tourism. All of these projects will help both the conversion of jobs and the creation of new jobs for young highly skilled professionals, and it would give space for modern development of the affected region. An important role for their realization is played by the already held out new fields of higher education in the region (at Trakia University in Stara Zagora), such as agrotronics, virtual technologies, bioeconomics, information technologies, software engineering, computer technology and others.

5. A key condition for implementation of each project and each economic initiative is to elaborate and apply mechanisms at the national, regional and local level in order to stimulate 
business capacity building in the affected areas, by greatly improving business skills and enhancing technology transfer. This requires two main directions of action - a policy of entrepreneurial activity and vitality and a policy to attract investment. The strong policy highlights for entrepreneurial activity in local communities are: knowledge of the needs of business; fostering the business success, incl. minimizing the administrative constraints; keeping up good business awareness; encouraging the local business products (goods and services) consumption; active support of the "knowledge triangle" in the region. The created conditions for new business investments will determine to a great extent the mix of industrial activities and the new economic structure of the region.

This transition must lead to the desired type of economy, which is driven by the circularity, bio-, RES- economics paradigm, environmentally responsible transport and sustainable development of the vulnerable regions. This includes a responsible thought and concern for future generations, to whom we have to leave underground riches to use in a new way that should go in line with the environmental protection, quality living standards and accomplished achievements in science and technologies.

With historical facts and set-in modern challenges, the integrated territorial development and active territorial innovations have no alternative as the most adequate and competitive model for development of the coal regions in transition and for the well-being of their communities. However, we would like to emphasize that this approach should be long-term and holistic, including social services and infrastructure, together with regional schemes of economic diversification, because it is about both economic and comprehensive territorial transformation.

\section{References}

1. Europen Commision, European Green Deal, https://ec.europa.eu/info/strategy/priorities-2019-2024/european-green-deal_bg

2. NSI, Emissions of pollutants in the air, https://www.nsi.bg/en/content/5082/emissionspollutants-air

3. A. Zinecker, Ph. Gass, Iv. Gerasimchuk, P. Jain, T. Moerenhout, Y. Oharenko An.R. Suharsono, Chr. Beaton, Real People, Real Change - Strategies for just energy transitions, Published by the IISD, (2018), https://www.iisd.org/publications/realpeople-real-change-strategies-just-energy-transitions

4. M. P. Mills, Mines, Minerals, and "Green" Energy: A Reality Check, [Online], https://www.manhattan-institute.org/mines-minerals-and-green-energy-reality-check

5. F. Gerber, K. Rademaekers, A just energy transition, opportunity for EU industries, the role of hydrogen in the future and the example of energy transition in Germany, Workshop Proceedings, 19 February 2019, European Parliament, Luxembourg (2019)

6. Y. Yarkova, Economic development of rural areas in Bulgaria, (Acad. Publ.Trakia University, 2012), ISBN 978-954-338-033-6

7. E. Hoover, Spatial economics: Partial Equilibrium Approach, in Encyclopedia of the Social Sciences, New York: Macmilan, innovation and interactive learning Printer, (London, 1968)

8. Denis de Rougemont "The Future is our Affair", (Zlatorog Publishing House, 1997), ISBN 954-437-048-X

9. H. Hoyt, Land Economics, 30(2), 182-186 (1954)

10. D. North, J. Polit. Econ., 63(3), 243-258 (1955) 
11. Ch. Tiebout, The community income multiplier: a case study, in R. Pfouts, (ed), The techniques of urban economic analysis, (London: Chandler-Davis, 1960)

12. E. Heckscher, The effect of foreign trade on the distribution of income 1919, in Readings on the theory of international trade, (publ. Philadelphia, Pa. [u.a.]: Blakiston, London, 272-300, 1949)

13. R. Harrod, Econ. J., 49(195), 14-33 (1939)

14. G. Borts, J. Stein, Economic growth in a free market, (New York, Columbia University Press, 1964)

15. N. Rost, Regional Economy Systems as Complement to Globalisation, (2007), [Online], http://www.regionalentwicklung.de/regionales-wirtschaften/uebersetzungentranslation/regional-economy-systems-as-complement-to-globalisation/

16. D. Bruno, Corvinus J. Sociol. Soc. Policy, 5(1), 35-59 (2014)

17. Moulaert, Sekia, Reg. Stud., 37(3), 289-302 (1999)

18. A. Weber, Theory CSISS Classics: Theory of the Location of Industries, (Chicago: The University of Chicago Press, 1929)

19. W.J. Reily, The Law of Retail Gravitation, (New York: Knickerbocker Press, 1931)

20. August Lösch, Was ist vom Geburtenrückgang zu halten? Heidenheim: Lösch, I: 73p, II: 95p. (1932)

21. International Labour Organization Guidelines for a just transition towards environmentally sustainable economies and societies for all. Geneva: ILO, (2015), https://www.ilo.org/wcmsp5/groups/public/---ed_emp/--emp_ent/documents/publication/wcms_432859.pdf

22. T. Hirsch, M. Matthess, J. Fünfgelt Guiding principles \& lessons learnt for a just energy transition in the Global South, (Friedrich Ebert Stiftung, 2017), http://library.fes.de/pdf-files/iez/13955.pdf

23. Iv. Stanchev, The change from within, in Handbook: The Captured Energy Transition, capital.bg, K Gradove, (2020), https://www.szeda.eu/docs/Capital-kspec_5839-all.pdf

24. Ministerstvo na energetikata, Ministerstvo na okolnata sreda i vodite, Integriran plan v oblastta na energetikata i klimata na Republika Bulgaria 2021 - 2030, 28, https://ec.europa.eu/energy/sites/default/files/documents/bg_final_necp_main_bg.pdf

25. European Trade Union Confederation (ETUC), Promishlenite regioni i politiki vuv vruzka s klimata: Perspektivi na profsuyuzite, 35

https://www.etuc.org/sites/default/files/publication/files/ces_low_carbon_economy_bu_ .pdf

26. Y. Yarkova, N. Markov, Kr. Toneva, Analysis and evaluation of the territorial economy in Stara Zagora district, in Proceedings of the scientific conference "Regional Economy and Sustainable Development", UE-Varna, 17 November 2017, Varna, Bulgaria (2018) 